\title{
LOOKING FOR RECONCILIATIONS BETWEEN ANECDOTES AND CAUSALITIES: THE STOICAL MODEL
}

Vinciane Despret

Jean-Marie LeMaire

ABSTRACT: Our bias in establishing causality ties which attribute to one consequence a unique cause make circular causality difficult as a way of thinking. Philosophy shows many theories about causality which all are ways to reduce anxiety. Our experiences sometimes require us to go farther than the instrumental (causal) level and to discover a place where disorder may be reestablished in the movement and contradiction. The Stoical model of expressive causality gives a different meaning to our work. In practice the anecdote becomes the essential element in a chair of expressive causalities. A clinical example shows how the anecdote can be the intersection between the family and therapist, offering a new dimension to circular causality and helps the therapist to understand and create another way of thinking about disorder and confusion.

The Stoical model has experienced in recent years with the development of cognitive therapy a revival of interest. Ellis in his rational emotive therapy (RET) based a part of his principles on the Stoic distinction between events which are dependent on one's will and events which are in the realm of one's desires over which one has no control. The Stoical philosophy, and its resulting therapy, is based on the

Vinciane Despret, professor of philosophy, and a psychologist; and Jean-Marie LeMaire, MD, a psychiatrist, are at the Institute Liegeois deTherapie Familiale, Centre de Recherche Dans Les Systemes Asbl, 72 Rue Hors Chateau, 4000 Liege, Belgium. 
principle that it is not the events which make people suffer but rather the perception they have of the events.

This aspect, happiness initiation, represents in the eyes of many the essential of the Stoical philosophy. But even in its origins this moral is a reaction to painful and confusing historical events; it is based on an original and unknown theory of causality. The question of distinguishing between events which are dependent on or independent of the person is a question which is closely related to the causal attribution (Seligman, 1975), that is to say, a theory of contingent causality affecting the subject in her or his interpretation.

\section{THE THEORY OF CAUSES IN THE ANTIQUE PHILOSOPHIES}

Aristotle was the first to elaborate a theory which asserted the totality of causal explanation of the event. The theory of the four causes-material, efficient, formal, and final-is limited in any case by the eternal relation between the subject (the creator) and the object (the created). Both are inscribed in the here and now. The cause of the finality could be considered as the anticipation of the result. It is this self-same anticipation which is inscribed in the present.

Let us imagine Aristotle creating a causality, for example, anecdotic. If we define it (and this is only an example of a possible causality) as the search for a remote event, apparently insignificant, which has as much impact as the material event which is efficient, formal, or final. For example, is not the fact that my grandmother had a Canadian fiance when she was 18 years old of the utmost importance for me, is not my loyalty inscribed in the causal field as surely as certain important decisions. The theory of family myth (Ferreira, 1977) throws light on this conceptual field.

Antique law is oriented toward the effort to reduce the event to an equation which permits the determination of the responsibility: the primary cause-causa proxima-was an effort to reduce the overwhelming richness of reality in movement.

If my grandmother's fiance has as much importance as my school result, my marriage, or my ruptures, one could argue that everything is cause (the determinist perspective or the obsessional perspective of the research) and that the search for this cause, as in all scientific research, is obligatorily reductionist in the manner that it reduces the quantity of information to make the reality clearer and more co- 
Vinciane Despret and Jean-Marie Lemaire

herent. It refers to a series of signs in the hermeneutical perspective which permit the distinction between the image (the event) and the background (the sum of the events).

The myth is an illustrative and contradictory example: in reality's confusion it is the defense against anxiety, the categorizing of opposites in order to establish orderliness in the world of a search for causes. Thus it reduces the confusion. It adds to this in consideration that the event, in the absence of the signification of the signs, would justify the present reality. The how and why are mixed in one theory. This reduces the anxiety, arranges the reality categorically and chronologically, and, at the same time, enlarges on the reality by adding information.

\section{THE STOICAL EXAMPLE}

The myth (family or ancient) brings us back to the heart of Stoical causality insofar as the myth brings into play a purely expressive modality; instead of explaining it, it is expressed in an interpretative manner. This perverted causality is rediscovered by Stoics as a central theme in their philosophy. This philosophy has been occulted by the progress of Cartesianism, a rational and linear philosophy, the geometrician's philosophy. According to the Stoics there are two qualities of causality. The first is the necessary cause which is the link between the physical cause and the cause subjected to the absolute necessity.

When in the causality relation one of the two elements (cause or effect) differs in nature from the other, in that one is corporeal, physical and the other is incorporeal, they foster a relationship of quasicausality, which is not a relationship of expression (Deleuze, 1963). All the quasi-causes form a system of signs between themselves which may be interpreted in an expressive scheme of causality in which necessity belongs to an official order called destiny (a sort of teleology of the system of causes). It is not the relations between the causes and effects but a unity of the correspondent quasi-causals forming a system of signs, briefly, a notional quasi-causality. The independence is installed in the presence of necessity.

This sort of causality brings us to Leibniz (1978), who interprets the event in a monadic world where everything is signs, symbols, and analogies which are significant at several levels, as in a fish pond in which each fish is itself a fish pond. What is the event which af- 
fects each of these parts? Everything in Leibniz's world is created and destroyed by harmonic or discordant correlations. The causality becomes con-possibility in the analysis of Michel Tournier (1977).

\section{BECAUSE OF ANXIETY}

If, as we believe, causality is the best therapy for anxiety, we must make an investigation from an ethical point of view of the price of the self-therapy in therapy when we encounter what we call a system (second remedy for anxiety), that is to say, a group of necessary laws and rules. This manner of interpreting reality is in itself a necessity in the way that it opened the field of knowledge and erased the sense of responsibility: no victim, no bully.

Our experiences sometimes require us to go farther than the instrumental level and to discover a place where disorder may be reestablished in the movement and contradiction. Heraclite and his enigmas which affirm, for one, that in a circle the beginning and the end are confounded, considering at the same time that the unity of reality is the multiplicity, that order is disorder. Only our anxiety prevents us from always facing up to it.

The space where the multiplicity can be reestablished would be a space regulated by the laws of Stoical causality-the notional quasicausality. In this space of disorder and confusion emerges this concept which gives a meaning to our work and which is the concept of the anecdote.

When, each evening, the guru sat down to proceed with the evening prayer the ashram's cat was in the way and distracted the monks so, he ordered that the cat should be attached during the evening prayers. A long time after the guru's death the cat continued to be attached during the evening prayer. Then, when the cat finished by dying, another cat was brought to the ashram so that it could be duly attached during the evening prayers. Centuries later the guru's disciples wrote wise treatises on the essential role of the cat in the good order of all prayers (DeMerlo, 1984).

In practice the anecdote becomes the essential element in a chain of expressive causalities. It is the intersection point between several stories united for a time, the familial time and the therapeutic time. 


\section{CLINICAL EXAMPLE}

The G. family consulted a mental health service. The oldest son, Christian, who was 11 years-old, was failing at school. He suffered from a pronunciation defect which made his speech inaudible. The youngest son, Clause, eight years-old and also a school failure, showed great immaturity. The daughter, Jessica, six years-old, showed no problems. The mother and father displayed important exterior signs of nervousness.

In addition to being failures in the school system, the children had fiery red hair which invited constant teasing from their fellow students. They were not alone in their marginality; none of the five members of the family had any contact with their relatives. Their financial difficulties and disturbing behavior had isolated them from all. The family had refused, in spite of a dramatic lack of resources, to ask for public assistance.

The two conversations during which their therapy request was analyzed took place in the greatest confusion. The agitation and the children's shouting made any oral communication almost impossible. The boys' attitude during the family sessions was strangely different from their attitude during individual conversations. During those consultations they were calm and showed greater reasoning power than their behavior during the family consultations had led us to expect.

A third consultation was held in order to negotiate a project to help the family in coordinating the children's learning problems. It took place in the evening. The children were equipped with flash lights. They used them to blind the intervenor. The family's electricity had been cut off because their debts did not permit them to pay the bill. The racket that the children provoked was worse than ever. No communication was possible.

\section{HYPOTHESIS AND CAUSALITY}

The G. family had retreated behind a rampart which protected it. The exterior scrutiny and the criticism made their failures heavier. The school, its rules and demands for success created a conflict of interest for the children. They chose a complete rejection of the values suggested by the school. By refusing scholastic integration, they in- 
creased the attention paid to them by the institutions concerned with this sort of malfunctioning.

The consultations dramatized the contradiction and rigidity of the role assignments. If the intervenor approached the boys' school problems, the older boy played his idiot role, twanging his comments with no direct relation to the present conversation; the younger one also assumed an idiot role and stuck to it. If the subject was changed and we dealt with the mother's nervousness or the family's financial management, one of the boys would get up, tease the other, and soon the three children would begin a dizzying round until the father became angry, got up, and controlled them, reestablishing order and permitting the mother to readjust the conversation by reminding the intervenor of the school problems.

The intervenor observed the causal chains, giving them a different accent, creating a global field of observation from which he was necessarily excluded. The merry-go-round of circular causality turned in front of the intervenor. He looked for the ticket which would allow him to climb on and go around if a change in the speed of rotation gave him a chance.

On the merry-go-round the children crunched sunflower seeds. During the visits in front of the intervenor-spectator they spit the shells on him. Covered with garbage, the intervenor had to choose loyalty to the system's theories or an attempt at anecdotic implication. At school 30 years earlier the intervenor had crunched the same kind of seeds and dissimulated the shells in his desk. Gravel from shells became momentarily the preponderant factor in the meeting.

The anecdote could become the frame of the conversation. It forced the intervenor to choose between two risks: to calm his anxieties by appraising the truth in the explicative models at his disposal at the risk of deepening the gap or to become involved in the anecdote's ridiculous fleeting liveliness at the risk of losing his identity as a competent intervenor in the game whose contract unites him to the family.

His interest increased when he noticed that one single package of seeds supplied the three children. The severe lack of resources did not prevent the parents from offering their children a snack. During the meeting's ups and downs the sunflower seed trading followed a strict pattern. The interest was further increased when the intervenor learned that the same kind of seeds helped the father to control his impatience at his work place. The children's father worked with his pockets filled with grain and crunched all day long in order to over- 
come the cramps in his jaws (which had already broken two teeth). He feels powerless, faced with the impossibility of providing his family with the necessary resources to subsist.

\section{DISCUSSION}

The anecdote, which dramatized the dead end where the intervenor's capacities are reduced to non-existence, can also revitalize the relational process if it is introduced in a new quasi-causal chair.

The circular causal hypotheses which reduce the anxiety create a more accessible reality. They constitute a necessary step categorizing impressions and constructing a myth (story, lies which tell the truth). Depending on the intervenor's choice, the anecdote takes its place in a causality chain where it lives for a fleeting moment carrying a parasitical or a paratherapeutic significance.

The Stoical model of expressive causality encourages us to consider this significance as long as it is necessary for it to provide the construction of a specific restricting environment in which the family and intervenor are trapped.

The reduction becomes the starting point for a new release of the energy it liberates.

\section{REFERENCES}

Deleuze, G. (1969). Logique du sens [Logic of meaning]. Paris: Les Editions de Minuit. DeMerlo, S. J. (1984). Comme un change d'oiseau [Like a bird's song]. Bruxelles: Desclee De Brouwere.

Despret, V. (1989). Philosophie et Reálité: le mythe et le vécu comme transition à la pensée abstraite [Philosophy and reality: Myth and personal experience as transition to the abstracted thought]. Namur: Eds. Provinciales.

Ferriera, A. J. (1977). Family myth and homeostasis. In P. Watzlawick \& J. H. Weakland (Eds. and Trans.), The interactional view (pp. 83-90). New York: Norton. (Reprinted from Archives of General Psychiatry, 9, 457-463. 1963).

Heraclite, (1988). In Les presocratiques [The presocraties). (Delatter trad). Paris: Gallimard.

Leibniz, G. W. (1978). La monadologie [Monadology]. Paris: Delagrave. (Original work published 1840).

Leibniz, G. W. (1966). Nouveaux essais sur l'entendement humain [New essays about human understanding]. Parit: Garnier-Flammarion. (Original work published 1797).

Seligman, M. (1975). Helplessness: On depression, development and death. San Francisco: W. H. Freeman.

Tournier, M. (1977). Le vent paraclet [The paraclete wind]. Paris: Gallimard. 